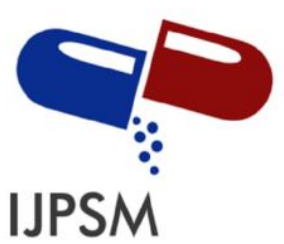

Bhushan Mali et al, International Journal of Pharmaceutical Sciences and Medicine (IJPSM), Vol.6 Issue. 7, July- 2021, pg. 128-152

ISSN: 2519-9889

Impact Factor: 3.426

\title{
Medicated Chewing Gum- A Patient Friendly Oromucosal Drug Delivery
}

\author{
Bhushan Mali ${ }^{1}$; P. B. Patil ${ }^{2}$; R. S. Bachhav ${ }^{3}$ \\ ${ }^{1}$ Ravindra Gambhirrao Sapkal College of Pharmacy, Anjaneri, Nashik-422213 \\ Email: malibhushan007@gmail.com \\ ${ }^{2}$ Faculty of Pharmacy, Ravindra Gambhirrao Sapkal College of Pharmacy, Anjaneri, Nashik-422213 \\ Email:pprashant32@yahoo.com \\ ${ }^{3}$ Principal, Ravindra Gambhirrao Sapkal College of Pharmacy, Anjaneri, Nashik-422213 \\ Email: bachhavrss@gmail.com \\ DOI: 10.47760/ijpsm.2021.v06i07.009
}

\begin{abstract}
Over the years, simplification of patients and patient-centered research in the field of drug delivery has led to the emergence of new drug delivery options. In them, chewing gum (MCG) had the means to give the simplest medicine, not only to special groups with problems of swallowing like children and the elderly, but also to all people, including the younger generation. The chewing gum contains a thin layer of masticatory gum coating that can be a film of polymers, waxes, sugar, flavors, or colors. A chemical ingredient can be present in the core, in the coating, or in both. The level of oromucosal absorption depends on the condition of the mucosa, the time of contact, and the physicochemical characteristics of the active ingredient. A small non-lipophilic molecule dissolved in enzymatic stable solids is more likely to penetrate. In the case of local action, it is possible to achieve beneficial results with a medicated chewing gum higher than that obtained by troches.
\end{abstract}

Patients in particular may view chewing gum as the preferred method of drug management compared to oral drinks or pills. The use of herbal remedies is possible as a local treatment for oral diseases and treatment of systemic conditions.

Keywords: Medicated chewing gum, patient convenience, Bioavailability, Oromucosal absorption.

\section{Introduction}

It is well known that a proper drug delivery system is essential to the success of a pharmaceutical product. The new drug delivery system creates additional patient benefits that will add new benefits to drug competition and thus increase revenue. The oral route is the preferred option between the patient and the nurses because of the various benefits it offers. One of the reasons the oral route has gained such popularity may be partly due to its easy handling ${ }^{(1)}$.

Chewing gum is a pleasure enjoyed by almost everyone. Chewing gum usually contains the gum spine, which can be inserted or closed. Chewing gums are defined by the European Pharmacopoeia and the dosage forms for prescription drugs issued in 1991 by the Committee on Medical Use in Human Medicine (CPMP) as 'one solid dose preparation with a gum base primarily intended for chewing but not swallowing, to provide more extract'. Chewing gum is also used in drug 


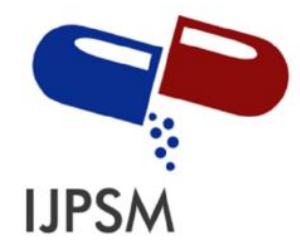

Bhushan Mali et al, International Journal of Pharmaceutical Sciences and Medicine (IJPSM), Vol.6 Issue. 7, July- 2021, pg. 128-152

ISSN: 2519-9889

Impact Factor: $\mathbf{3 . 4 2 6}$

delivery and is often referred to as the mobile drug delivery system. Medicinal chewing gum (MCG) provides local (oral treatment) as well as systemic action (buccal suction or swallowing saliva). MCG helps increase patient adherence through faster onset and improved drug availability as a certain amount of drug is absorbed through the buccal mucosa. It can also be supplied without water ${ }^{(2)}$.

Medicated chewing gum used over the years has gained increasing acceptance as a novel drug delivery system. Several ingredients have now been incorporated into therapeutic chewing gum, e.g. fluoride prophylaxis for dental caries, chlorhexidine as a local disinfectant, nicotine for smoking cessation, aspirin (acetylsalicylic acid) as an analgesic, dimenhydrinate for motion sickness, and caffeine as a preparation for 'staying' be careful '. There are many other conditions and diseases in which there is a possibility of the use of herbal gum ${ }^{(3)}$.

\section{Advantages of Chewing Gum: ${ }^{(1,4,5)}$}

1. Fast/rapid onset of action

2. High bioavailability

3. Pleasant taste

4. Easy for administration without water promotes higher patient compliance

5. Ready to use formulation

6. High acceptance by children and for patients who find swallowing tablets difficult are obvious

7. Fewer side effects

8. Systemic effect

9. Local effect

10. Effect on dry mouth (xerostomia)

11. Product distinctiveness from a marketing perspective.

\section{Disadvantages of Chewing $\operatorname{Gum}^{(6,7)}$}

Chewing gum has several disadvantages as

1. The drug released in saliva disappears quickly from the oral cavity because of involuntary swallowing.

2. The concentration of medication in the oral cavity is tends to lowering as a result of salivary dilution.

3. The drug release from chewable formulations has strongly influenced by the way patient chews the MCG.

4. The presence of the delivery system in the oral cavity causes disturbance in drinking, eating and speaking therefor administration of such dosage form is restricted to short period of time.

5. Facial muscle pain and ear ache in children.

6. Allergy to chewing gum composition such as flavor and sweetening agents. 


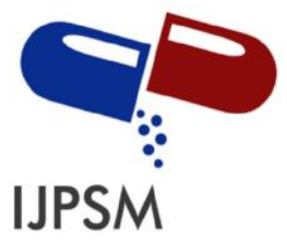

Bhushan Mali et al, International Journal of Pharmaceutical Sciences and Medicine (IJPSM), Vol.6 Issue. 7, July- 2021, pg. 128-152

ISSN: 2519-9889

Impact Factor: 3.426

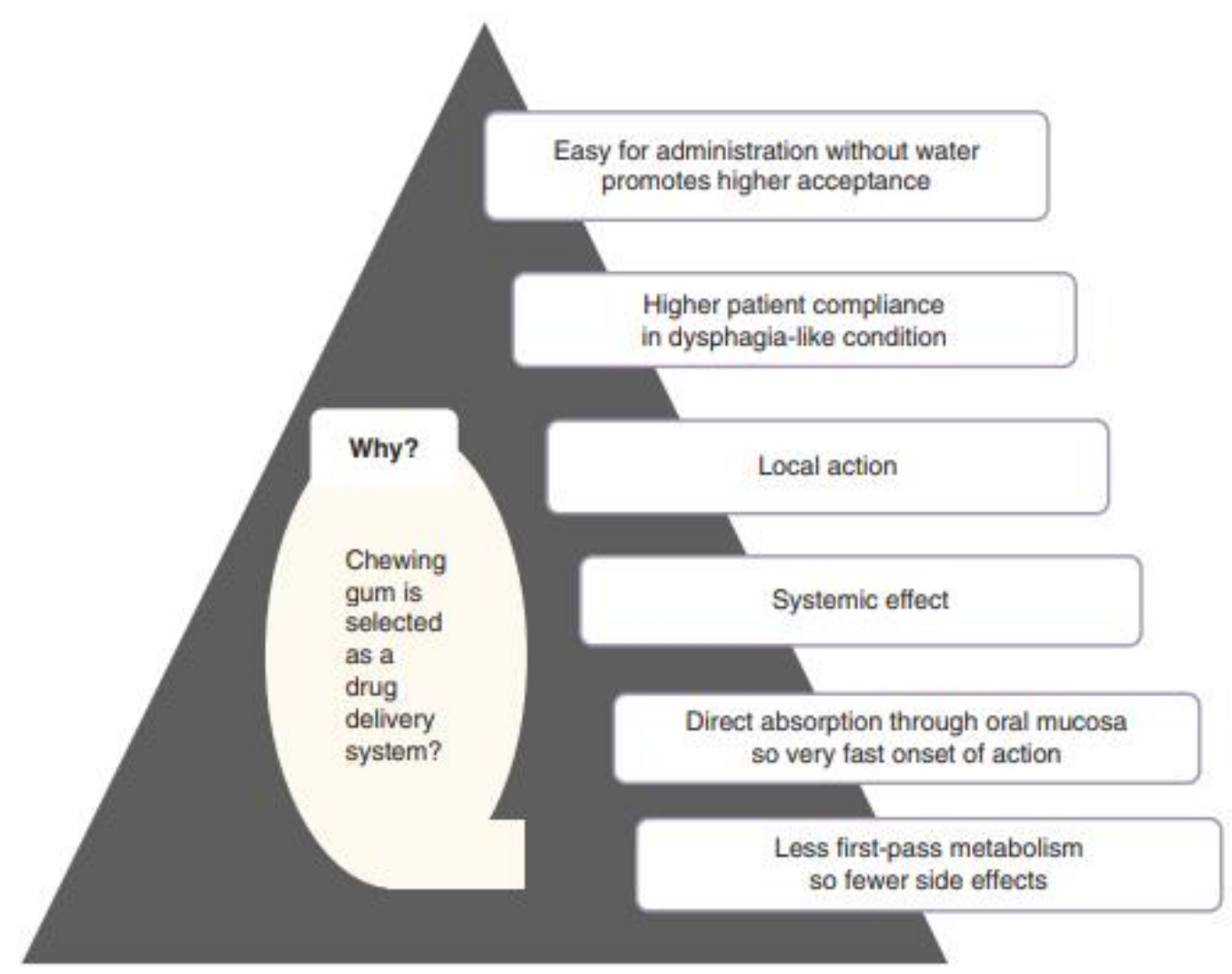

Figure 1: Reasons for Selection of MCG as a Drug-Delivery System 


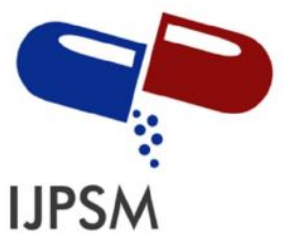

Bhushan Mali et al, International Journal of Pharmaceutical Sciences and Medicine (IJPSM), Vol.6 Issue. 7, July- 2021, pg. 128-152

ISSN: 2519-9889

Impact Factor: 3.426

Table 1: Main Components of Medicated Chewing Gum and their Function / Characteristics ${ }^{[8,9,10,11]}$

\begin{tabular}{|c|c|c|c|c|}
\hline Components & $\begin{array}{l}\text { Preferred } \\
\text { composition of final } \\
\text { gum (outer range) } \\
{[\%]}\end{array}$ & $\begin{array}{l}\text { Examples of } \\
\text { composition } \\
\text { of gum base } \\
\text { (outer range) } \\
\text { [\%] }\end{array}$ & Function/characteristics & $\begin{array}{l}\text { Examples of } \\
\text { excipients }\end{array}$ \\
\hline Gum base & $\begin{array}{l}20-40 \\
40-90 \\
15-30 \\
10-50\end{array}$ & & Saliva-insoluble materials & \\
\hline Resin/rosin & & $<10(0-75)$ & $\begin{array}{l}\text { Delivery of active ingredient, plastic } \\
\text { Derivatives of rosin texture, binder, } \\
\text { prevents 'bite through', anti-adhesive } \\
\text { to teeth and denture }\end{array}$ & $\begin{array}{l}\text { Derivatives of } \\
\text { rosin }\end{array}$ \\
\hline Elastomers & & $\begin{array}{l}40(35-45) \\
4-16(0.5-25)\end{array}$ & Provide elasticity and cohesion & $\begin{array}{l}\text { Styrene- } \\
\text { butadiene, } \\
\text { polyisobutylene, } \\
\text { polyvinylacetate, } \\
\text { polyethylene, } \\
\text { natural rubber }\end{array}$ \\
\hline $\begin{array}{l}\text { Softeners and } \\
\text { plasticizers }\end{array}$ & & $\begin{array}{l}0-10 \\
5-15(0.1-20) \\
1-10(0-15)\end{array}$ & $\begin{array}{l}\text { Reduce viscosity to a desirable } \\
\text { consistency, improve mouth feel, } \\
\text { improve chewability }\end{array}$ & $\begin{array}{l}\text { Glycerol } \\
\text { monoacetate, } \\
\text { stearic acid, coca } \\
\text { butter, glycerin, } \\
\text { lecithin }\end{array}$ \\
\hline Emulsifiers & & & $\begin{array}{l}\text { Promote saliva uptake into the gum, } \\
\text { Lecithin, glycerolmonosterate } \\
\text { thereby facilitating release of active } \\
\text { ingredient and flavor }\end{array}$ & $\begin{array}{l}\text { Lecithin, } \\
\text { glycerolmonoste } \\
\text { rate }\end{array}$ \\
\hline Fats, waxes & & $\begin{array}{l}15-20(0-25) \\
8-15(2-25)\end{array}$ & $\begin{array}{l}\text { Provide 'slip' and prevent 'bite } \\
\text { through' }\end{array}$ & $\begin{array}{l}\text { Microcrystalline } \\
\text { wax, paraffin } \\
\text { wax, bee wax }\end{array}$ \\
\hline Fillers & & $\begin{array}{l}10-20(0.1-30) \\
20-30(0-60)\end{array}$ & $\begin{array}{l}\text { Provide texture, improve chewability } \\
\text { provide a reasonable size of gum } \\
\text { lump with low dose }\end{array}$ & $\begin{array}{lr}\mathrm{MgCO}, & \mathrm{CaCO}, \\
\mathrm{MgSi}, & \mathrm{AlSi}, \\
\mathrm{CaPO} & \end{array}$ \\
\hline Antioxidants & & $<0.1$ & $\begin{array}{l}\text { Protect other components from } \\
\text { oxidation }\end{array}$ & $\begin{array}{l}\text { Butylated } \\
\text { hydroxy toluene }\end{array}$ \\
\hline
\end{tabular}




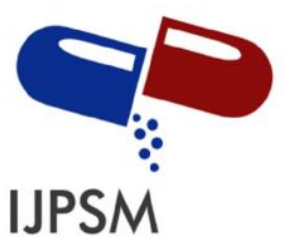

Bhushan Mali et al, International Journal of Pharmaceutical Sciences and Medicine (IJPSM), Vol.6 Issue. 7, July- 2021, pg. 128-152

ISSN: 2519-9889

Impact Factor: 3.426

\begin{tabular}{|c|c|c|c|}
\hline Buffers & $2-5(0.1-10)$ & $\begin{array}{l}\text { Create a constant } \mathrm{pH} \text { environment } \\
\text { inside the mouth, keep the un-ionized } \\
\text { form of active ingredient (thereby } \\
\text { facilitating absorption to systemic } \\
\text { circulation), facilitate release of } \\
\text { active ingredient }\end{array}$ & \\
\hline Coating & & $\begin{array}{l}\text { Protect active ingredient(s) and gum } \\
\text { Shellac, celluloses, syrups base from } \\
\text { light, moisture and oxygen, deliver } \\
\text { flavor and/or active ingredient(s) }\end{array}$ & $\begin{array}{l}\text { Shellac, } \\
\text { celluloses, } \\
\text { syrups }\end{array}$ \\
\hline Sweeteners & $\begin{array}{l}30-35(20-75) \\
55-85(0.05-90)\end{array}$ & $\begin{array}{l}\text { Improve palatability, mask } \\
\text { unpleasant taste of active ingredient }\end{array}$ & $\begin{array}{l}\text { Glucose, } \\
\text { sucrose, xylitol, } \\
\text { sorbitol, } \\
\text { Mannitol }\end{array}$ \\
\hline Flavors & $\begin{array}{l}0.1-5(0-10) \\
0.8-1.2(0.3-1.5)\end{array}$ & $\begin{array}{l}\text { Improve palatability, mask } \\
\text { unpleasant taste of active ingredient }\end{array}$ & \\
\hline Colors & $<1$ & $\begin{array}{ll}\text { Distinguish different } & \text { active } \\
\text { ingredients from each other } & \end{array}$ & \\
\hline
\end{tabular}

\section{Concept of Formulation Development: ${ }^{(12,13)}$}

A piece of tissue usually contains the gum spine, which may or may not be attached. The substance is composed of insoluble resin, elastomers, emulsifiers, fillers, waxes, antioxidants and softeners, sweeteners, flavoring agents, and in the case of chewing gum, active ingredients. The water content of the gum is very low and does not required any preservative. Since most active substances are lipophilic, they will adhere to the base of the gums so they can be released slowly and irregularly. The bioavailability of drug withdrawal can be increased with the addition of buffering agents or solubilizing agents as well as coating of active ingredients. Conversely, hydrophilic substances are released quickly so you may need to slow down the release by inserting active ingredients or by increasing the amount of gums. The water content of the gum base is very low and the gum binds lipophilic material tightly. To get the right make-up you are likely to reduce the rate of release, choose highly lipophilic substances and increase the rate of lipophilic release.

To be successful in the market, chewing gum must have a pleasant taste and texture. The base of the gums determines the basic characteristics of the product such as texture, softness, hardness, firmness, swelling, adhesion, mouthfeel etc.

\section{Chewing Gum Formulation}

The composition and amount of gum base are factors that affect the release of an active ingredient. Changing the lipophilic by hydrophilic ratio of gum will delays the release of an active ingredient. Gum becomes more lipophilic by 


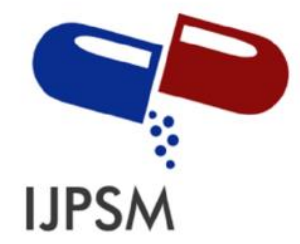

\section{Bhushan Mali et al, International Journal of Pharmaceutical Sciences and Medicine (IJPSM), Vol.6 Issue. 7, July- 2021, pg. 128-152}

ISSN: 2519-9889

Impact Factor: $\mathbf{3 . 4 2 6}$

increasing the amount of base gum thereby reducing the rate of active ingredient release. The texture of gum can affect the rate of an API. Increasing amounts of lubricants on the base of the gums can provide faster discharge and the harder base of the gums can provide slower discharge.

The strong structure of the active lipophilic ingredient, nicotine, bound to the resin exchange resin allows for a continuous drug delivery system. If the excretion rate is too high, a large portion of the excretion rate may be swallowed, which can cause adverse effects on the intestines. Incorporating the buffer system can also increase oromucosal absorption. The buffer system adjusts the $\mathrm{pH}$ level in the saliva during the first few minutes of chewing. The $\mathrm{pH}$ value of the non-ionized nicotine form is preferred as the non-ionized form is easily absorbed. The cyclodextrins are cyclic oligosaccharides, which contain a hydrophobic hole and a hydrophilic surface. Typically, cyclodextrins enhance the aqueous solubility of active ingredients or non-soluble ingredients in water by forming infusion structures. Patented documents describe gum made from cyclodextrin products with the proliferation and prolonged release of many active ingredients for a local or systemic effect. The properties of the Cyclodextrin infusion of diluted soluble drugs enable the heat of the drug and increase the rate of dissolution from chewing gum.

Many other methods of modifying and controlling the release rate of an active ingredient from chewing gum are described in the patents, e.g. encapsulation with various techniques for spraying or coating, blending to provide partial wrapping, removal of absorbing adsorption, or a combination of these methods. In addition, the active ingredient can be added to the outer cover for immediate release and added to the gum section with or without encapsulation for slow release. Covering techniques can have limited options as many coats are destroyed during chewing gum.

\section{Manufacturing Process: ${ }^{(12,18)}$}

The general process of gum production is as follows. The base of the gums was to be softened or melted (between 50 and $70{ }^{\circ} \mathrm{C}$ ) and placed in a large container and well drained. The mixture is then cleaned using a filter tool and high-speed centrifuges. The sweeteners, softening and flavoring agents, mixed with the gum base on machines with strong curling irons, produce weight in the consistency of solid bread dough. The weight of the gums is transmitted by a series of rollers, which are made into a thin, wide ribbon, slightly coated with powdered sugar (to prevent sticking) and obtained (cut and broken) into single sticks. Gum is designed to extend shelf life. The product is packaged and ready for distribution. The whole process takes from 5-15 min, but the duration of the mixing can depend on the composition and function of the base of the gum used.

\section{Composition of MCGS: ${ }^{(19-21)}$}

Generally, chewing gum is made by combining two components: a continuous soluble water phase containing nonmasticatory ingredients, such as API, plasticizers, flavors, and sweetener; and a non-abrasive phase (base of masticatory gum base), which consists mainly of gums as the basic materials needed in any composition to provide chewing gum structure with a rubber-like structure. The base of the gums is also used to carry sugary substances, flavors, or anything else in chewing gum. It is usually found in values ranging from 5 to $60 \%$, by the weight of the final chewing gum.

\section{Water-Insoluble Phase (Primary Phase): ${ }^{(22-27)}$}

Traditionally, the first category or flavored gum is an unmixed and insoluble ingredient found in natural ingredients or in elastomers. Natural rubbers can contain natural latex such as Jelutong, Lechi Caspi, Perillo and Chicle. The Sapodilla tree 


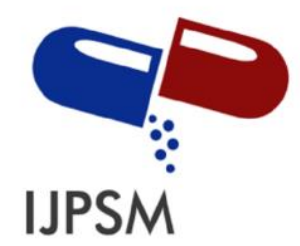

\section{Bhushan Mali et al, International Journal of Pharmaceutical Sciences and Medicine (IJPSM), Vol.6 Issue. 7, July- 2021, pg. 128-152}

ISSN: 2519-9889

Impact Factor: 3.426

is one of the largest sources of natural chicle gum. Chicle gum is made up of polyterpenes composed of thousands of subunits of $\mathrm{C}_{5} \mathrm{H}_{8}$ isoprene (2methyl-1,3butadiene). It was a key ingredient in chewing gum. To this day, the chicle is extracted from the sap of the sapodilla tree and used in several chewing gums. However, Chicle is expensive and difficult to obtain and use if the required properties such as compliance and adherence are required. The bases of the gums used today and therefore mostly have artificial origin. They are very complex and rely on the interaction of various special ingredients to ensure the desired performance. Unfortunately, the exact formation of artificial gum foundations is not readily available in textbooks. Copyright revisions show that many compounds have been incorporated into the gum bases to provide some performance. Currently, many ingredients in gum bases are listed and regulated by the organization's code of conduct. Typically, common gum comes from a synthetic origin consisting of elastomer (10-40\%), elastomer solvent (2-18\%), polyvinyl acetate (15-45\%), emulsifier (2-10\%), waxes (0-10\%), plasticizers (20-30\%), and fillers $(0$ $70 \%)$.

\subsection{Elastomers}

Elastomers are one of the most important ingredients in modern gum bases. They are inactive and non-digestible foods with viscoelasticity that provide the structures of the gum labels and digestion. Elastomers provide the desired body and rubber texture and cohesiveness. The gums made of most elastomers are not weak, while high concentrations give the gums harder and rubberry. The name elastomer is derived from the elastic polymer, which is often used consistently with the word rubber. Naturally, they are polymorphic amorphous composed of long chains of atoms, especially carbon, hydrogen, and oxygen, which have some degree of interaction with neighboring chains. Bonding bonds provide the elastomer with a unique material to reconstruct the original form when removing the impotence. Typical elastomers are styrene-butadiene rubrene (SBR) and polyisobutylene (PIB) rubrene. In the manufacture of chewing gums, PIB, although more expensive, is more widely used than SBR which does not have the required body composition to make soft gums.

\subsection{Polyvinyl Acetate}

Polyvinyl acetate (PVA) is a synthetic resin prepared by the polymerization of vinyl acetate monomer. It is found in the range of different molecular weights. In chewing gums, it works to control the balance between the firmness and the base of the gum base. Improves gum blending by blending and helping to bind elastomers and other ingredients such as fillings. The addition of PVA to elastomers reduces the adhesion and adhesion of the gums to the teeth while providing a good cohesiveness of the chewing gum that causes them to deform and disintegrate easily during chewing. PVA is not only important for obtaining the desired texture and chewing properties, it also contributes to the removal of flavors and sweeteners from the base. Low-molecular-weight PVA usually has high lubrication properties and low viscosity, resulting in greater penetration of bonding strength and less binding strength than those that are more pronounced. At higher levels, they lead to stronger gum and plastic foundations.

\subsection{Elastomer Solvents (Resins)}

Elastomer solvents or frames are used to soften the elastomer and make it easier to work with. They provide durability, flexibility, and a combination of gum, which are essential for maintaining balance between elastic property and plasticity. Gum bases with high plasticity are strong and tough. Terpene compounds such as alpha-pinene or beta-pinene polymers, methyl, glycerol, or pentaerythritol esters are widely used as solvents. While excessive use of dye causes the gums to stick to the surface of the teeth, low levels lead to unacceptable chewing properties. 


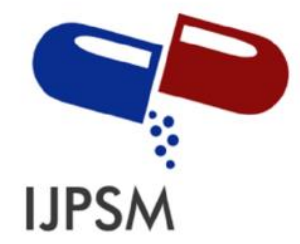

Bhushan Mali et al, International Journal of Pharmaceutical Sciences and Medicine (IJPSM), Vol.6 Issue. 7, July- 2021, pg. 128-152

ISSN: 2519-9889

Impact Factor: $\mathbf{3 . 4 2 6}$

\subsection{Emulsifiers}

Emulsifiers primarily act to soften the base of the gums by the combination of eutectic and lipid elements. They improve texture and soften the base to get higher chewing properties, which are important for improved oral sensitivity. They also provide hydration by promoting water retention and the absorption of saliva during chewing, acting as carriers of colored agents and flavors, and improving the gum's ability to form bubbles when applied to bubble-chewing gums. They also act as carriers of coloring agents and flavoring agents. Most of emulsifiers contains lecithin, glycerol monostearate and also acetylated monoglycerides. More than $1 \%$ lecithin has been used to soften the gums in demand, and high values can lead to unstable product such as paste-like product.

\subsection{Plasticizers}

Plasticizers are small molecules that promote flexibility in the bases of the gums leading to desirable formation and adhesion. They transform the mechanical properties made from gum material from solid and leafy material into a soft and flexible product. They also improve their elasticity or flexibility by changing the temperature of the base glass (Tg). Plasticizers should be compatible and not compatible with the gum base. They can be added directly to the gum base as part of the gum base itself, which usually saves a large amount of plasticizer or as part of the water-soluble part of the gum base, which often reduces the effectiveness of plasticizers leading to an easily disengageable product in the mouth. Although the addition of plasticizer to the construction of the first gums may seem to be the solution to this problem, it can provide the first gum to be able to listen to the consumer. Selected plasticizers include triacetin, lecithin, p. glycol, natural dietary solvents and glycerin. Although not widely used, it has been shown that low molecular weight polyethylene glycols, such as PEG 200, 300, or 400, can be used as plasticizers to make unbroken chewing gum made from protein-containing substances such as zein.

\subsection{Fillers and Waxes}

Fillers are particles that are used as texture changers and bulking agents when applied in low doses or strong chemicals. Common fillers include low-density powders such as calcium carbonate, magnesium carbonate, and talc. They tend to provide better chewing areas by reducing the stiffness of the base of the gums in the teeth. They are used to reduce the overall cost of chewing gum. Fillers, such as oily silica and talc, have been used as antiadherents during production to improve the flow of hoppers or to reduce the adhesion of chew gum granules to the surface of fists and death walls during compaction. Wax, in some cases, can be used instead of fillers as bulking agents. They are also used to install elastomers in part to reduce production costs. Recently, however, concerns have been raised in the UK about their use in the gums. As a result, the bases of wireless gums were developed and tested. Typical waxes include microcrystalline, paraffin, candelilla, and carnauba waxes.

\subsection{Active Pharmaceutical Ingredients}

APIs or drugs are included in MCGs for therapeutic purposes. They can be incorporated to the lipophilic gum cavity or a hydrophilic coat and sometimes both. The final form can contain up to $30 \%$ drug content $(\mathrm{w} / \mathrm{w})$. The release of drugs from chewing gums depends on their physiological characteristics. For example, low-soluble drugs are released less and 


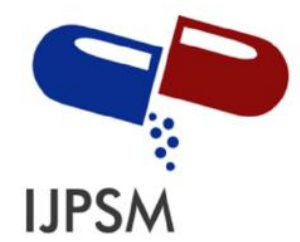

Bhushan Mali et al, International Journal of Pharmaceutical Sciences and Medicine (IJPSM), Vol.6 Issue. 7, July- 2021, pg. 128-152

ISSN: 2519-9889

Impact Factor: $\mathbf{3 . 4 2 6}$

less efficiently compared to water-soluble drugs. Therefore, special construction techniques and ingredients are required to produce a suitable release profile. Drugs suitable for chewing gum should have an acceptable taste, small particle size $(<100 \mu \mathrm{m})$, low molecular weight, compact, stable anti-salivary enzyme, non-toxic to the mouth, and do not cause tooth decay and oral decay.

\section{Water-Soluble Phase (Non masticatory or Secondary Phase): ${ }^{(22,27,29)}$}

The base of the gums is often combined with melted sugar water or sugary drinks to give taste and flavor before they are digested and formed into sticks, sheets, or tablets. During chewing, the water-soluble phase dissolves over time. To improve the mouth feel, it is desirable to extend the release. Several methods have been used to measure the release of sweeteners and flavor agents from chewing gums, such as microencapsulation and absorption. Strategies for the inclusion of sweets have been disclosed in many U.S. Patents.

\subsection{Sweeteners}

Sweeteners represent, in some cases, about 50 to $60 \%$ of the base of the gum base. They are available in liquid or bulky form. Liquids such as hydrogenated starch hydrolysates and corn syrups, also soften the moisture retention effect. Many sweeteners include sugary substances such as sucrose, dextrose, maltose, dextrin, and fructose. Due to their delicate texture, the particle size of this sugar must be small. Recently, the use of sugary drugs, such as sorbitol, manitol, and xylitol, has become quite common, especially in the digestive gums. Xylitol is especially popular due to its cooling effect (endless heat of salvation) and is often combined with low-cost polyols. High-intensity sweeteners such as aspartame, glycyrrhizin, saccharine, and acesulfame salt can also be added to chewed gums to give the impression of long-lasting pleasure. The refinement of these sugars is usually from 0.005 to $3 \%$ of gum formation.

\subsection{Flavoring Agents}

Flavors, whether natural or artificial, can be added to the composition alone or in combination with other flavors based on patient preference and follow-up. The use of flavors in MCGs can overcome the bitter taste of the drug. They may also act as gum filters, affecting the texture of the gums. The addition of flavors, however, may not be enough to soften the chewing gum when used alone, instead it should be added with plasticizers to achieve a chewing quality. The best gum plasticizers are flavors with essential oils such as citrus oils, peppermint oil, and clove oil. Typically, flavors are used in low concentrations of about 0.4 to $1 \%$. The extract of flavors from chewed gums depends on their thermodynamic parameters and its $\log \mathrm{p}$ (octanol / water partition coefficient) or $\log _{\mathrm{c}} \mathrm{P}$ (coefficient for gum / water separation).

\section{Manufacturing of MCGS: ${ }^{(22,24,30)}$}

Chewing gums can be done under GMP guidance in one of three main ways: (I) traditional/ conventional method; (II) cooling, grinding, and tableting method; and (III) direct compression method. The choice between these methods depends on the type of chewing gum, the active ingredients, and the strength of the composition. 


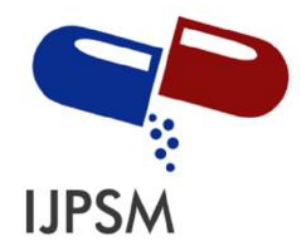

Bhushan Mali et al, International Journal of Pharmaceutical Sciences and Medicine (IJPSM), Vol.6 Issue. 7, July- 2021, pg. 128-152

ISSN: 2519-9889

Impact Factor: $\mathbf{3 . 4 2 6}$

\subsection{Traditional/Conventional Method:}

The normal process of producing MCGs begins by applying heat to the first melting step. In this step, the solid gum base and synthetic polymer are softened or dissolved at a mixing temperature between 50 and $90{ }^{\circ} \mathrm{C}$, using hot water or steamed kettles, to achieve a consistent fluid with appropriate viscoelastic properties. In subsequent mixing steps, the temperature is kept close to the lubricant (temperature between the glass temperature and the mixing point) to keep the gum base fluid rubber mixed with other ingredients such as fillers and APIs within a specified time, with flavors added to finally produce the same compound. . Gum ingredients are incorporated into extruders and sent to a cooling system where gum structures such as elasticity and firmness are changed. In the cooling system, the temperature is controlled and reduced to make chewing gum easier to form into sheets obtained, then transferred to a series of rollers to flatten the sheets and smooth the texture. Spreadsheets are then obtained with small pellets with a hardness between 16 and $20^{\circ}$ Shore coating with sugar syrup. Finally, the bound gum is waxed and ready for packing.

\subsection{Cooling, Grinding, and Tableting Method:}

In this way, the base of the gums is first melted in the oven and placed in a mixture containing other gum ingredients. During mixing, the composition is cooled by a cooler, such as solid carbon dioxide, or by placing the solids in a cold liquid such as liquid nitrogen until it hardens into a solid mass. This allows the gums to form into chewing powder. The digestive process is challenging due to the adhesion of chewing gum particles, which can be overcome by adding $2-8 \%$ by the weight of grinding aid such as alkaline metal phosphate or maltodextrin.

The active ingredients, such as vitamins or minerals or herbs, and other ingredients are then incorporated into the gum powder, and the compounds are ground to a pulp to form granules that can be pressed to form pellets or formed into other chewing products.

\subsection{Direct Compression Method:}

The direct compression method uses compacted gum material designed in the form of a powder to produce a chewing tablet. Health in $\mathrm{Gum}^{\circledR}$, for example, refers to a group of free-flowing substances such as gums developed by Cafosa Gum SAU. These directly pressing gums contain high percentage of thermoplastic elastomers, a combination of polyols (sorbitol / xylitol / mannitol), sugars, plasticizers, and anticaking agents. When pressed, Health in Gum® leads to a combination similar to the appearance of prescription pills. They are harder and more resilient than chewing gum. They also have a different impact on API release. Nicotine gums made with direct pressure had a faster release rate than Nicorette ${ }^{\circledR}$ designed for conventional methods. Life in Gum ${ }^{\circledR}$ is available in three grades: HiG PWD-01, HiG PWD-03, and HiG PWD-04, which contains 25, 35, and 30\% gums respectively. They have a low moisture content, which increases the shelf life of active embedded molecules. 


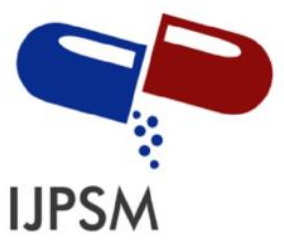

Bhushan Mali et al, International Journal of Pharmaceutical Sciences and Medicine (IJPSM), Vol.6 Issue. 7, July- 2021, pg. 128-152

ISSN: 2519-9889

Impact Factor: 3.426

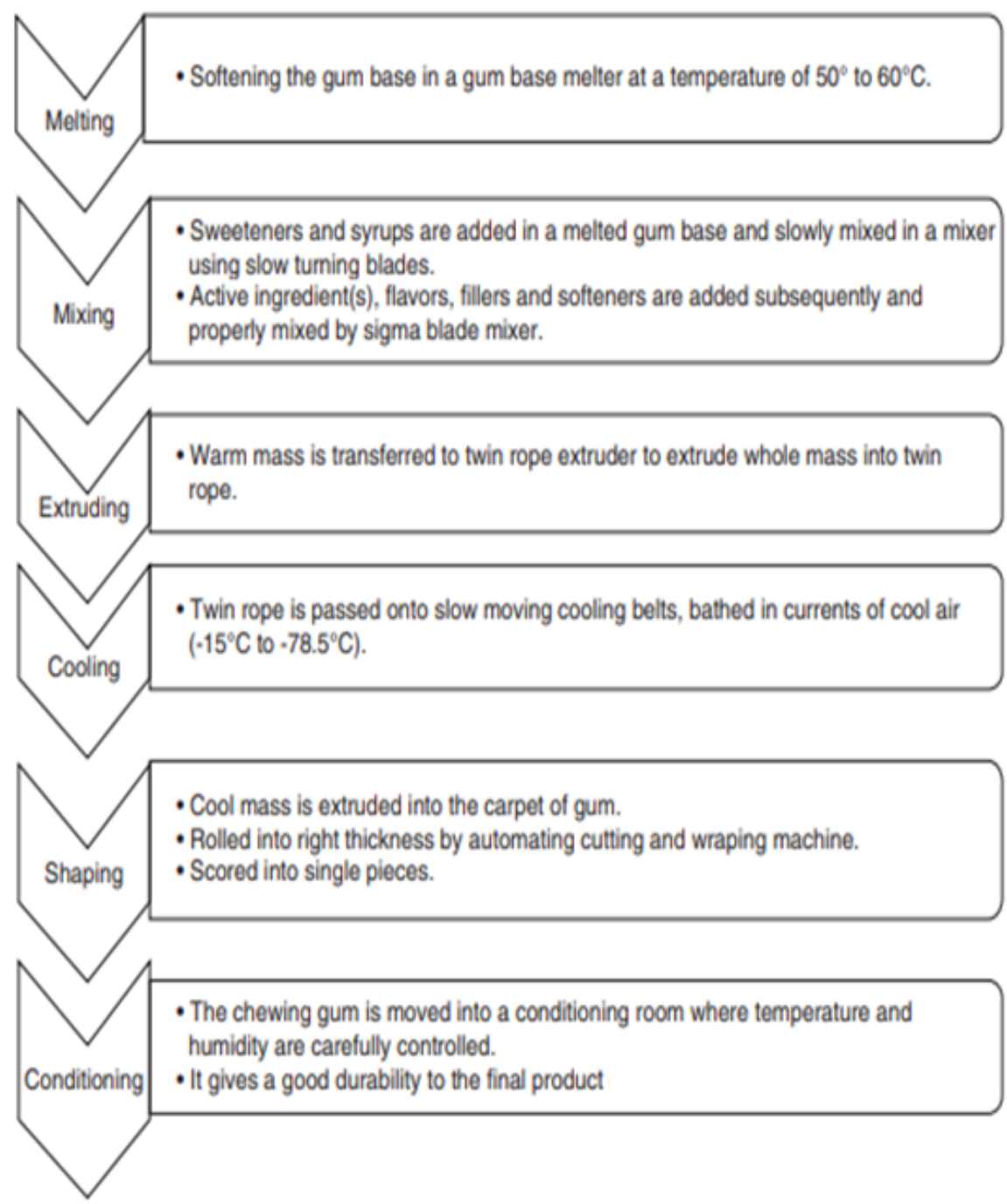

Figure 2: A Schematic Representation of the various Processing Steps involved in Manufacturing of MCG by the latest Technology 


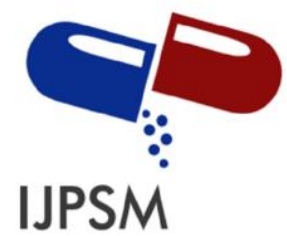

Bhushan Mali et al, International Journal of Pharmaceutical Sciences and Medicine (IJPSM), Vol.6 Issue. 7, July- 2021, pg. 128-152

ISSN: 2519-9889

Impact Factor: $\mathbf{3 . 4 2 6}$

\section{Evaluation and Characterization of MCGS: ${ }^{(22,29-31)}$ 11.1 Official Product Quality Tests:}

The following MCG screening methods were reported in Ph. 8 Ph. Eur under chapters 2.9.5, 2.9.6, and 2.9.7 in terms of weight, contained in single-dose settings, and the stability of the unlocked tablet, respectively.

\subsubsection{Uniformity of Mass}

The same quantity is often used for uncooked chewed gums. It is made by measuring the weight of twenty pieces of gum and calculating the percentage of deviation of the weight of each grain from the average weight according to the Formula:

$\%$ Weight loss $=($ average weight - Individual weight/average weight $) \mathrm{X} 100$

To comply with the $\mathrm{Ph}$. Eur, no more than two units of chewing gum should deviate from the average weight of more than $7.5 \%$ of medium-heavy gums $\geq 300 \mathrm{mg}$ and $10 \%$ of medium-heavy gums $\leq 300 \mathrm{mg}$. content uniformity test is used when the average gum weight is $\geq 40 \mathrm{mg}$.

\subsubsection{Content Uniformity}

The consistency of the content or content of chewing gum is determined using the appropriate analysis method to confirm the uniformity of units of single dose preparation dose. According to $\mathrm{Ph}$. Eur, there are three content similarity tests (CU) (A, B, and C). Test A is designed to test pills, while tests $\mathrm{B}$ and $\mathrm{C}$ are designed for pills and transdermal patches, for acceptance. MCGs as rigorous evaluation forms should comply with the A CU test limits. Test A is used for MCGs that contain $2 \mathrm{mg}$ of the API or if the API is less than $2 \%$ of the total weight of the chewing gum. Determined to measure API content by ten chewing gum units. Each part of the gums should have a drug content within the range of 85 and $115 \%$.

\subsubsection{Friability Test}

To test the friability of the compressed gums, ten gum units, if the unit weight exceeds $650 \mathrm{mg}$ [or $6.5 \mathrm{~g}$ of accumulated weight if the unit mass is less than $650 \mathrm{mg}$ ] is randomly selected and carefully dusted before testing. Initially, the gums are weighed $\left(\mathrm{W}_{\text {initial }}\right)$ and then placed in a container. After that, the drum is allowed to rotate 100 times at $25 \mathrm{rpm}$. The gums were then dusted off and weighed again $\left(\mathrm{W}_{\text {final }}\right)$. The weight difference represents the percentage of friability ( $\mathrm{F} \%$ ) that can be calculated based on the Formula:

$\mathrm{F} \%=\left(\mathrm{W}_{\text {initial }}-\mathrm{W}_{\text {final }} / \mathrm{W}_{\text {initial }}\right) \mathrm{X} 100$

MCGs pass the friability test if the $\mathrm{F} \%$ is less than $1 \%$.

\section{Unofficial Product Quality Tests}

As compared to other dosage forms, medicated chewing gums have mastication property. The pleasant texture of this dosage form is essential to their commercial success. Currently, official pharmacopeias have not specify a 


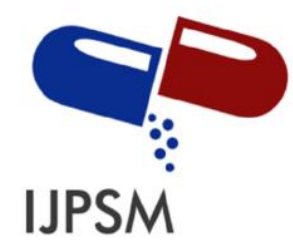

\section{Bhushan Mali et al, International Journal of Pharmaceutical Sciences and Medicine (IJPSM), Vol.6 Issue. 7, July- 2021, pg. 128-152}

ISSN: 2519-9889

Impact Factor: 3.426

complete testing procedure for the estimation of the mastication properties, mechanical, and textural properties of MCGs. Therefore, different testing procedures have been developed and cited in the literature with the aim of estimating the mechanical properties of MCGs. A brief overview of the most pertinent tests is given below.

\subsection{Texture Profile Analysis}

Texture profile analysis (TPA) is an important tool used to assess the properties of food products. Mechanical properties are determined by subjecting a bite size of material in 2 compression cycles (two bites test) in a reciprocating motion that activates the motion of jaws where high compression force is used to mimic chewing of the teeth. This test creates a curve for migration response when several parameters of text corresponding to the sensory test can be removed and converted to chewing gum. The first high value in the first cycle is related to the difficulty of the items tested. The appearance of small peaks during the first cycle prior to hardening is an indication of the strength of the bullet. The strength of the internal bonds in the tested objects is defined as the sum, calculated from the ratio of the positive points below the curve in the first and second cycles. The mechanical behavior of the test object after the dissipation of the applied power and the withdrawal of the pressure processor may be related to its overflow, which can be measured from the time interval between the first points of the two cycles. Chewiness is a second parameter that can also be found in rated parameters; is calculated as the repetition of complexity, concentration, and speed. The data provided by Al Hagbani and Nazzal showed whether it is possible to use TPA to monitor changes in MCG text structures with a growing number of drug loads. It was also used to determine the upper limit of solid content before the loss of their grinding properties. For two bite tests, it is recommended to use a $4 \mathrm{~mm}^{2}$ compression processor. In another study, a circular probe with a $45^{\circ}$ cone angle was believed to be more suitable for chewing gum because of its identified geometry. By using this probe, the reduction is minimized and minimized the undesirable error that may occur during the retaliatory movement.

\subsection{Elastic Recovery and Plasticity}

The most important material for MCGs is its chewing, which is a direct function of its durability and plasticity. Measuring a force-displacement curve with a precise pressing mechanism is one of the methods that can be used to study and evaluate the powerful irreversible process of chewing gum. Such measurements have been shown to be helpful in understanding the chewing gum of medicines. In this way, the upper and lower fists of the tablet machine are fitted with measuring gauges to measure the power used and transducers to track the distance. From the dynamic migration curve, pressure parameters such as effective work (E2), elastic recovery (E3), and plastic can be determined. After high pressure, when the upper fist begins to move upwards, the stretch marks indicate some recovery. It is believed that the ability to drive a flexible recovery force (i.e., van der Waals forces, strong bridges, electrostatic forces, and hydrogen bond) and the strength and elasticity (stress) are maintained in the particles during hardening. The elastic regeneration that begins immediately after the compression phase is caused by the rearrangement of the macromolecule in the bases of the gums under pressure. Some ingredients such as APIs and fillers do not provide for easy retrieval. Plasticity, on the other hand, measures the deformity of an object during compression. Calculating the amount of plasticity and elastic recovery (E3) during compression with a table setting improves our understanding of the trend of the object being tested. From the installation of the table, the minimum recovery rate is preferred. Elastic recovery (E3) and plastic recycling can be calculated from the Equations. 


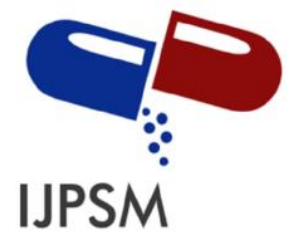

Bhushan Mali et al, International Journal of Pharmaceutical Sciences and Medicine (IJPSM), Vol.6 Issue. 7, July- 2021, pg. 128-152

ISSN: 2519-9889

Impact Factor: 3.426

$\mathrm{E} 1=\frac{\mathrm{Fmax} C}{2}-(\mathrm{E} 2+\mathrm{E} 3)$

E2 $=\int_{A}^{B} F$ upper ds-E3

E3 $=\int_{B}^{D} F$ upper ds

Plasticity $=\frac{E 2}{E 2+E 3} X 100$

Where $\mathrm{F}_{\max }$ is the maximum force during compression, $\mathrm{C}$ is displacement, $\mathrm{F}_{\text {upper }}$ is the maximum force measured on the upper punch, and ds is the elemental value of the displacement transducers.

\subsection{Plasticity Index}

To measure plasticity Index (PI), a molten gum base is transferred to an aluminum weight pan with specific diameters and depth. After cooling for $24 \mathrm{~h}$, indentation experiment is performed with the help of texture analyzer fitted with a spherical probe. In this test, the probe is allowed to move at a fixed speed for a specific distance into the gum base, which will have the same thickness of the weight pan. From the trigonometric calculation of the sphere, the theoretical chord value (TCV) for a given depth and diameter can be obtained, while the experimental chord value (ECV) can be measured using a regular Vernier caliper. Plasticity Index is calculated based on the EC value to TC value ratio for each sample as follows in Eq. (5):

$$
\mathrm{PI}=\frac{\text { Expermintal chord value after } 24 \mathrm{~h}(\mathrm{~mm})}{\text { Theoreical chord value after } 24 \mathrm{~h}(\mathrm{~mm})}
$$

To measure PI it is suggested to study the effect of lubricants or plasticizers on the polymeric / continuous gum base phase. It has also been used to examine the relationship between different types of cosmetics and their effect on flavor extraction. Adhesive gums have high deformation and low PI with values close to 0 , while plastic gums have high PI with approximate values.

\subsection{Penetration Test ${ }^{(33)}$}

This test was used to understand the functional impairment of MCGs performed by direct pressure or by fusion / traditional method. Checks the response to modified object modification in in-depth investigation. This test was performed with a texture analyzer equipped with a 1.5-2-mm stainless steel probe that was allowed to enter the gum at a speed of $0.5-2 \mathrm{~mm} / \mathrm{sec}$ at a depth of 3 millimeter. Once the desired depth is reached, the maximum negative 


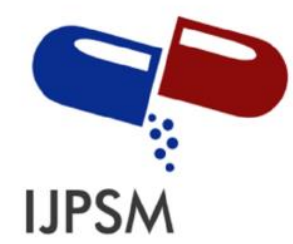

\section{Bhushan Mali et al, International Journal of Pharmaceutical Sciences and Medicine (IJPSM), Vol.6 Issue. 7, July- 2021, pg. 128-152}

ISSN: 2519-9889

Impact Factor: $\mathbf{3 . 4 2 6}$

value will be detected as a result of the retracted action. The force encountered by an probe is calculated by plotting a distance and time. The highest peak in a corner that has led to forced migration is a measure of the strength of the gums or the resistance to biting, while the highest peak during the withdrawal of the probe is related to the stiffness or adhesion of the gums. Using this trial, Morjaria et al. It has been shown that nicotine chewing gums that are made in a straightforward manner using a compression gum directly (Pharmagum ${ }^{\circledR}$ ) have higher or stronger density than nicotine chewing gums. They also found that a sharp rise in the line of gum-powered gums caused by direct pressure was followed by a sudden decrease in strength due to cracking, and a gradual decrease in overtime was observed with gums made by compounding due to plastic transformation. The separation of the gums caused by direct pressure under pressure was thought to be a combination of gums in which Pharmagum ${ }^{\circledR}$ was physically mixed with other solids, and by a combination, the base of the gums formed a similar matrix to other gum ingredients.

\subsection{Tensile Test}

Tensile tests are not widely used in chewing products since the digestive process requires pressure, not tension. However, it can be used to measure the stiffness of chewing gums. The stiffness of the gums contributes to enhanced follow-up of patients. It also contributes to drug withdrawal. This test is performed using a solid solvent machine where a piece of gum rests between two connectors. In a test, chewing gum is pulled over the wire and stretched until it fails or loses firmness. With this process, estimates of the size of the mechanical properties such as yield strength, final strength, and modulus of elasticity or Young's modulus can be obtained from the compressive set. Pressure and hardness can be calculated based on the sample location, the length of the original sample, the elasticity, and the applied force. Ductile artificial materials such as chewing gum comply with Hook's law by demonstrating a consistent line of line between pressure and strain, where deformity is found entirely in the removal of pressure. If the stretch is too long, chewing gum may increase. As the tension increases, the pressure and difficulty no longer obey Hook's law, leading to a non-linear response in which the chewing gums become deformed and do not fully return to their original size and to the construction of the inserted type. Tensile tests were used on various bases of the gums and showed that the level of filling such as calcium carbonate has a negative impact on the strength of the gums.

\subsection{Indentation Test}

Chewing gum pills are different from regular ones. Unlike standard tablets, compressed gums are designed to be chewed. They do not break completely after the first bite; instead they are deformed and / or fragments into smaller pieces. The hardness of standard tablets can be easily measured by several compression tests that can measure the strength required to break the tablet. On the other hand, gum pills that require special assembly to evaluate and monitor their disability process. Texture analyzers are used to record the force-displacement curve to study the deformation process of chewing gums. When using a texture analyzer, chewing gums are placed on a flat platform and inserted inside with a 3-mm knife with rounded edges at a test speed of around $3 \mathrm{~mm} / \mathrm{s}$. In the event of a modified hardness tester, the power sensors (Unicell load cell $200 \mathrm{~N}$ ) are used to assist in making the migration force curve. Studies have shown that the pain of chewing gum tablets under the applied force indicates a curve of adhesion made of plastic. At first the chewing gums become severely deformed until they are exhausted until 


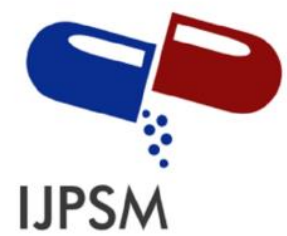

\section{Bhushan Mali et al, International Journal of Pharmaceutical Sciences and Medicine (IJPSM), Vol.6 Issue. 7, July- 2021, pg. 128-152}

ISSN: 2519-9889

Impact Factor: $\mathbf{3 . 4 2 6}$

harvest, after which they become deformed with plastic and come in contact with a large amount of chewing gum. The power output is required to permanently break and / or disable the plums by chewing. It is used to test the strength of a gummy object. During plastic transformation, a gradual decrease in resistance to applied force as the probe progresses into a non-chewing rate can be used to measure the tendency of the gums to detect plastic defects. Plastic is, in general, related to chewing. By using this trial, the effect of power and gum pressure on the MCGs was demonstrated. It has also been used to illustrate the gradual change in the mechanical properties of metal tablets with the increase in drug loading.

\section{In-vitro Release Testing of Drugs from MCGS: ${ }^{(31-33)}$}

Because of their gum nature, MCGs are not eligible to be tested with standard degradation testing equipment used with standard pills or pelletes. Since MCGs need to be chew and not swallowed, in-vitro testing of drug extracts in the gums is a definite step in their commercial growth. Various machines have been developed to mimic the chewing process. Ph. Eur (8th ed) published standard monographs describing two apparatuses, A and B, to study invitro extraction of chewing gum. Testing for chewing gum has not been officially approved by USP 40-NF 35, although monographs for individual nicotine polacrilex gums for product quality testing such as assay, identification, unit size, content and mass are provided.

\subsection{Apparatus A:}

The official dissolution system A approved in 2000 by Ph.D. Eur is shown in Fig. 3. In apparatus A, the chewing gum sample is placed in a temperature-controlled chewing chamber and forwarded to mechanical forces by 2 horizontal pistons which rotate around their axes in opposite direction after each chew at same speed that mimics the mastication. A vertical piston (tongue) is used to ensure that the frame stays in the correct position. The speed of chewing, the medium-sized volume, the distance between the jaws, and the twisting movements may vary. Ph. Eur recommends using $20 \mathrm{~mL}$ of $\mathrm{pH} 6$ phosphate buffer solution in a 40-mL chewing room and a chewing rate of 60 lashes per minute. Drug release information obtained from this device, however, is not widely available or published in the public domain. 


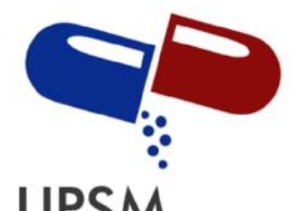

Bhushan Mali et al, International Journal of Pharmaceutical Sciences and Medicine (IJPSM), Vol.6 Issue. 7, July- 2021, pg. 128-152

ISSN: 2519-9889

Impact Factor: 3.426

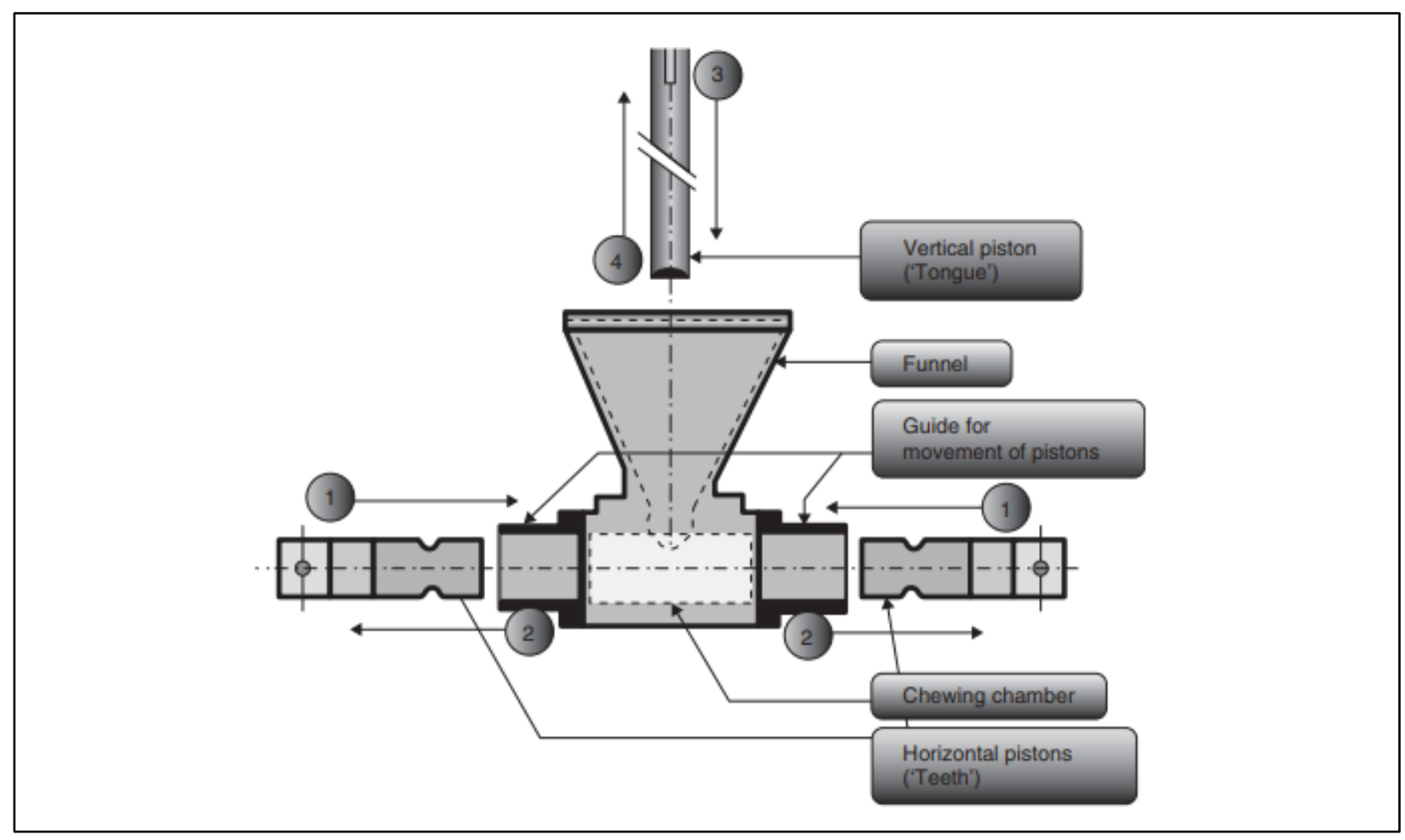

Figure 3: Schematic representation of modified dissolution apparatus as per European Pharmacopoeia, where numbered arrows indicate sequence of motion. ${ }^{(32)}$

\subsection{Apparatus B:}

Apparatus B to test for drug withdrawal in MCGs was designed by Wennergren. It has been widely accepted with numerous reference works. The layout diagram of these resources is shown in Figure 4a. It consists of six temperature-controlled chewing gum channels each with pistons facing upwards representing the upper and lower chewing jaws. During the test, the gum is placed on the surface of the lower jaw. The chewing process involves the repetitive movement of the lower jaw combined with a twisted movement of the upper face that supports the molding and provides adequate movement of the testmedium. The upper chewing gum sits next to the middle part of the lower extremity, with a narrow edge facing upwards at $45^{\circ}$ to prevent the gum from slipping during the grinding act. Tool settings can be easily adjusted and adapted to each drug product. 


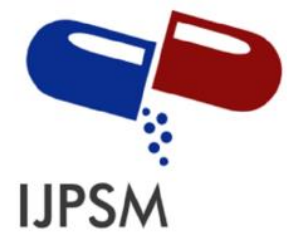

Bhushan Mali et al, International Journal of Pharmaceutical Sciences and Medicine (IJPSM), Vol.6 Issue. 7, July- 2021, pg. 128-152

ISSN: 2519-9889

Impact Factor: 3.426

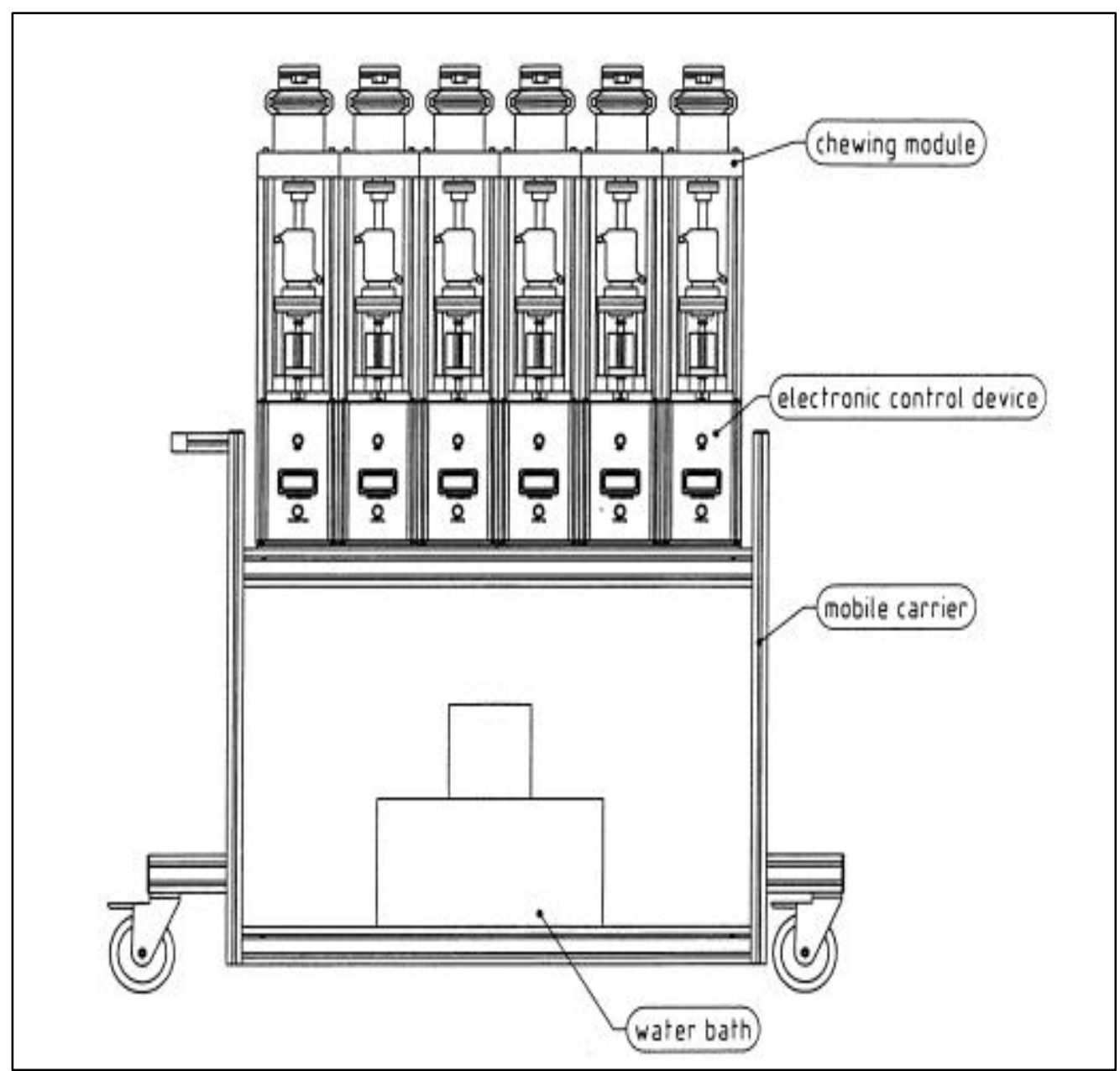

Figure 4a: Technical Drawing of the Chewing Apparatus. The entire setup showing the six chewing modules. 


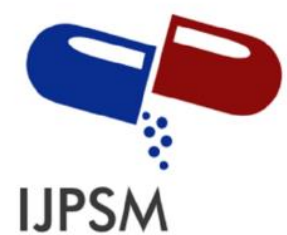

Bhushan Mali et al, International Journal of Pharmaceutical Sciences and Medicine (IJPSM), Vol.6 Issue. 7, July- 2021, pg. 128-152

ISSN: 2519-9889

Impact Factor: 3.426

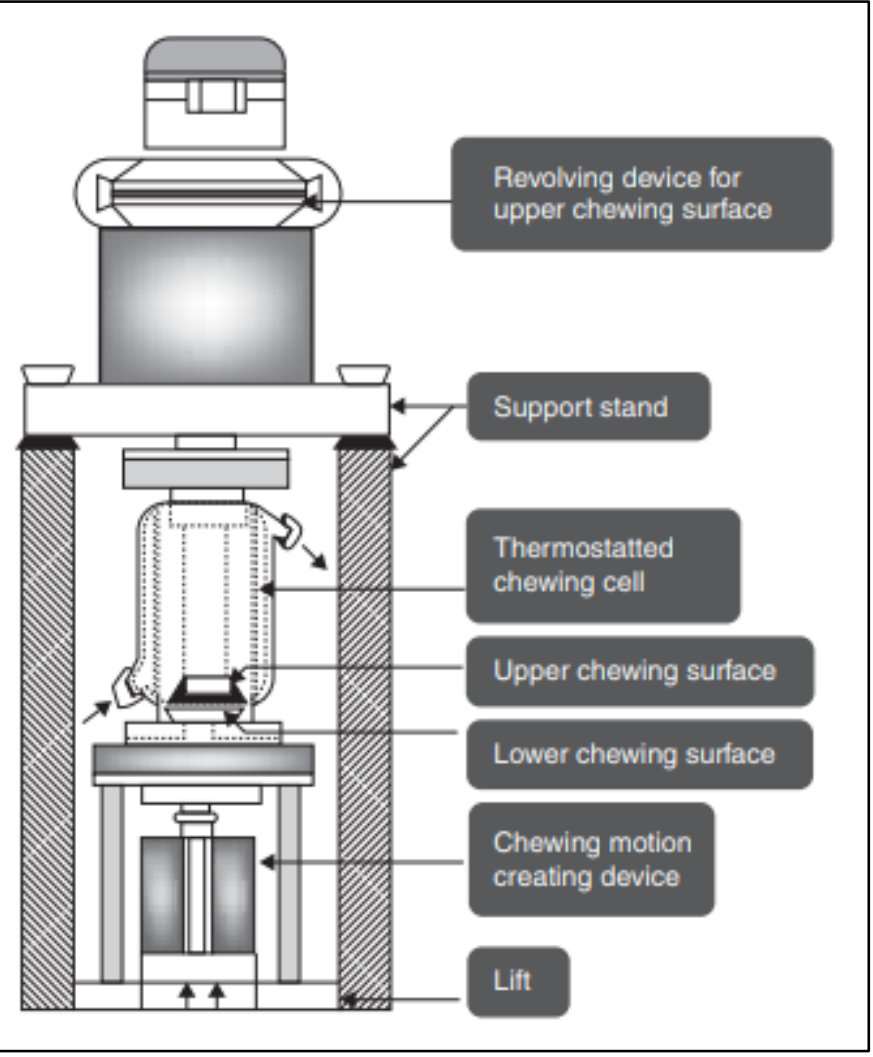

Figure 4b: Schematic representation of Unofficial Single Module Chewing Apparatus

\section{Factors Affecting the Release of Active Ingredient 14.1 Time of Contact: ${ }^{(34)}$}

Achievement of a local or system effect can be depended on the chewing time, eg the contact time for the extraction and termination of the active ingredient, unless it is released within a few minutes of chewing. The acceptable time to chew gum can reflect a wide range of people. The estimated chewing time for each piece was 36 minutes in the study with 4064 participants. Chewing time of 30 minutes in a clinical trial is considered to be close to normal use.

\subsection{Person-to-Person Variability ${ }^{(32)}$ :}

One of the reasons why MCG has not been completely exploited is because of the uncertainty of treatment related to the delivery of drugs - that is, the mechanical chewing action of a patient. The effect of chewing gum depends on the process of chewing and as each person has his or her own chewing power, frequency and time of chewing, the results may vary. Barabolak et al. use the reporting questionnaire to determine the length of the chewing time (in minutes). The recommended chewing time for each piece of meat was $36 \mathrm{~min}$, so they suggested that when designing a clinical trial, a chewing time of $30 \mathrm{~min}$ should be used if the results would be added to the normal use of 


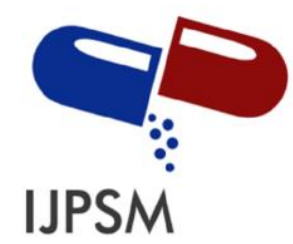

\section{Bhushan Mali et al, International Journal of Pharmaceutical Sciences and Medicine (IJPSM), Vol.6 Issue. 7, July- 2021, pg. 128-152}

ISSN: 2519-9889

Impact Factor: $\mathbf{3 . 4 2 6}$

chewing gum. The degree to which the chewing gum affects the amount of medicine extracted. The standard chewing rate is $\sim 60$ chews per minute. For this purpose, nicotine extracts have been extracted from Nicorette in various amounts. In that study it was found that a chewing rate of 1 chew every second gave a significantly $(\mathrm{p}<$ 0.05 ) more release of drug than a chewing rate of 1 chew every $8 \mathrm{~s}$. An in-vitro study determined by the European Pharmacopoeia shows that 60 strokes per minute is sufficient for the proper release of an active ingredient.

\subsection{Physicochemical Properties of Drug:}

The physicochemical properties of the active ingredient such as its cell size, ionized or non-ionized form, lipophilicity or hydrophilicity, stability to salivary enzymes (amylase) and its solubility in saliva play a vital role in extracting the drug from MCG and drug infiltration through the oral mucosa. For example, the saliva-soluble ingredients will be released immediately within a few minutes, and the soluble drugs are first extracted from the gum base and gradually into saliva secretion. Water-soluble API plays a key role in the removal of gum formation, i.e., the release of soluble drug (water solubility> 1:10), in total, 75\% or more within five minutes of chewing and $90 \%$ or more during 15 minute of masticating at a rate of 60 chews in a 60 seconds. Water-soluble drugs between 1:10 and 1: 300 show up to $60 \%$ excretion during 10 minutes of chewing and between 50 to $90 \%$ excretion after 15 minutes of chewing. The concentration of soluble drug (1:1000) was found at $<5 \%$, even if the gum was chewed for 30 minutes.

\subsection{Formulation Factors ${ }^{(34)}$ :}

The composition and quantity and type of base of the gums, solvents and moisturizing agents can affect the rate of active ingredient release from MCG. For example, the release of miconazole is not good if it is added directly to the gum. In-vitro extraction studies using a chewing machine and in-vivo studies using healthy adult volunteers have shown that the strong dispersion of miconazole-PEG 6000 (1: 4) in letter formation produced a greater rate of extraction than pure miconazole. This is because PEG 6000 increases the solubility of miconazole in water. While lecithin is added to the formation of miconazole-PEG chewing gum both the rate of release and the timing of miconazole release significantly increased in-vitro and in-vivo. In another study, the effect of gum weight on drug release was studied using salicylamide as a indicative. When salicylamide was added to the gum containing the largest percentage of gum base, the gum base output was very low, $25.6 \%$, compared to chewing gum where there was a small gum base, i.e., $52.0 \%$.

\section{Application of Medicated Chewing Gums: ${ }^{(35-36)}$}

Chewing gum not only offers scientific benefits but also is an eye-catching, unique and effective drug delivery system. The prospect of chewing gum will reflect all the scientists' efforts to improve chewing gum as a recent drug delivery system. In the future, there will be more reports of making more drugs using chewing gum as a drug delivery system. Treatment of fungal infections, preventing caries, smoking cessation, long-lasting taste, fullness of the gums, timely discharge are some of the trendy products that will be seen in the future. Now a days biodegradable chewing gums are also in demand. Numerous studies have shown that taking chromium picolinate supplements as a gum can reduce insulin levels and cause insulin receptors to accept its effects. Gum can be used to treat minor headaches and muscle aches. The composition of chewing gum containing nicotine and lobeline has been clinically proven to be effective in eliminating smoking. Active ingredients such as chromium, guaran, and caffeine have been 


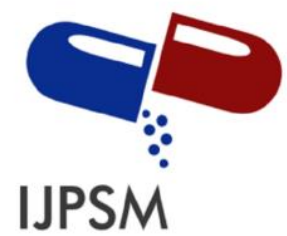

\section{Bhushan Mali et al, International Journal of Pharmaceutical Sciences and Medicine (IJPSM), Vol.6 Issue. 7, July- 2021, pg. 128-152}

ISSN: 2519-9889

Impact Factor: $\mathbf{3 . 4 2 6}$

shown to be effective in treating obesity. Chromium is recommended to reduce appetite due to improved blood glucose levels. Caffeine and guaran stimulate lipolysis and reduce appetite. Xerostomia, allergies, motion sickness, cold and cough, diabetes, anxiety, etc. Experimental studies, including patients with oral candidiasis have shown that miconazole chewing gum is at least as satisfactory as miconazole oral gel in the treatment of oral fungal infections. In a recent study, the stability of KSL-W, decapeptide antibodies, and its potential as an antibacterial agent in the formation of chewing gums have been shown to interfere with the development of plaque-related pathogens. Wamer-Chilcott Inc. developed the Ovcon 35, a chewable birth control gum having spearmint flavour. Some of the most recent applications of medicated chewing gum are described as follows.

\subsection{Tooth Whitening Property:}

Attempts at tooth whitening have long been thought to originate in ancient Egypt. Over-the-counter products naturally contain carbamide peroxide or hydrogen peroxide as a bleaching agent. Chlorine dioxide is known as a sterilizer and a powerful oxidizing agent. Chlorine dioxide are also known for its Bactericidal, algaecidal, fungicidal activity. bleaching and deodorizing elements are also there for it. These chlorine dioxide properties have led to the formation of medicated chewing gum, which include an active agent which is one of the components that produces chlorine dioxide, a solution containing chlorine dioxide, and its compounds.

\subsection{Probiotic Gum:}

Internal, whole or concentrated chewing gum containing probiotics such as Lactobacillus acidophilus, Lactobacillus reuteri, Lactobacillus plantarum, Lactobacillus salvalarius, Lactobacillus sporogenes, Bi'dobaterium longum, etc. are produced. The probiotic transmitted orally for health benefits to customers by suppressing pathogenic bacteria.

\subsection{Psychospirituality:}

Psycho-spirituality, is defined as the study and practice of mental relationships with natural, moral and ethical ideas. The invention of the nutritious chewing gum containing the plant Salvia divinorum serves as a means of stimulating human understanding and thinking in a way that enhances the whole mental mind.

\subsection{Anesthetics:}

Establishments related to oral pain relief, and especially to chewing gum to help relieve pain in orthodontic procedures. Dental implants can have an unwanted effect on a patient's chewing, daily performance, and sleep. Chewing gum includes lidocaine and prilocaine hydrochloride as an anesthetic, as well as a chewing gum.

\subsection{Hypophosphatemia}

The creation of a non-therapeutic use of the phosphorus compound in chewing gum and the binding agent chitosan, to reduce the level of free phosphorus in digestive juice to reduce hyperphosphatemia. 


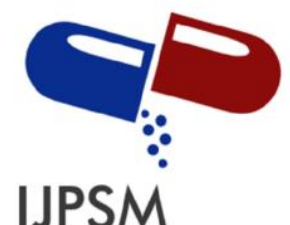

Bhushan Mali et al, International Journal of Pharmaceutical Sciences and Medicine (IJPSM), Vol.6 Issue. 7, July- 2021, pg. 128-152

ISSN: 2519-9889

Impact Factor: $\mathbf{3 . 4 2 6}$

Table 2: Marketed Medicated Chewing Gum for Pharmaceuticals and Nutraceuticals. ${ }^{(32,33)}$

\begin{tabular}{|c|c|c|}
\hline Marketed MCG & Active ingredient & Indication \\
\hline Aspergum & Aspirin (acetyl salicylic acid) & Pain relief \\
\hline Orbit white & Calcium as a tricalcium phosphate & $\begin{array}{l}\text { Dental hygiene and for tooth } \\
\text { whitening }\end{array}$ \\
\hline Fluogum & Fluoride as a sodium fluoride & Prevention of dental caries \\
\hline Travvel gum & Dimenhydrinate & Motion sickness \\
\hline Niquitin cq & Nicotine & Smoking cessation \\
\hline Hexit & Chlorhexidine & Antibacterial \\
\hline Stay alert & Caffeine & CNS stimulant \\
\hline Endekay & Vitamin C (ascorbic acid) & Vitamin supplement \\
\hline Zoft virility gum & $\begin{array}{l}\text { Extracts of Hawthorn Berry, Horny Goat Weed, } \\
\text { Damiana Leaf, Muira Puama Root, Ginkgo } \\
\text { Biloba Leaf, Ginseng Root, Catuaba Bark } \\
\text { Extract, Saw Palmetto Berry }\end{array}$ & $\begin{array}{l}\text { Increases male sexual desire and } \\
\text { performance }\end{array}$ \\
\hline Chew away gum & $\begin{array}{l}\text { Extracts of Hoodia gordonni -- nature's calcium } \\
\text { channel blocker }\end{array}$ & $\begin{array}{l}\text { Appetite suppressant for weight } \\
\text { loss }\end{array}$ \\
\hline Zoft menopause gum & $\begin{array}{l}\text { Extracts of Dong Quai Root, Black Cohosh } \\
\text { Root, Damiana Leaf, Mexican Wild Yam Root }\end{array}$ & $\begin{array}{l}\text { Symptomatic relief from post- } \\
\text { menopausal syndrome }\end{array}$ \\
\hline Zoft stress gum & $\begin{array}{l}\text { Extracts of Ashwagandha, Passion Flower and } \\
\text { Jujube Fruit and Calcium carbonate }\end{array}$ & $\begin{array}{l}\text { Reduces the symptoms associated } \\
\text { with stress, anxiety and depression }\end{array}$ \\
\hline
\end{tabular}




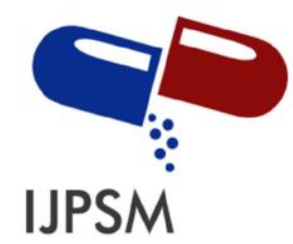

\section{Bhushan Mali et al, International Journal of Pharmaceutical Sciences and Medicine (IJPSM), Vol.6 Issue. 7, July- 2021, pg. 128-152}

ISSN: 2519-9889

Impact Factor: $\mathbf{3 . 4 2 6}$

\section{Marketing Advantages as a Business Opportunity ${ }^{(31,32,34)}$}

There is a need to redesign an existing drug into new drug delivery systems (NDDS) to extend or protect product patent, thereby delaying, reducing or preventing general erosion in patents. By building these drugs in the formulation of MCG, the revitalization of old products and the reorganization of new patented products is possible, separating and future market competition. Danish gynecologist Fertin Pharma is a leader in the field, with its MedChew technology attracting interest to a few medical players. One of the major advances in this partnership is its MetControl project with the American company Generatex Biotechnology, which focuses on the formation of gum containing metformin for the treatment of diabetes. In June 2008, Gennesx reported clinical data showing that MetControl is equivalent to the construction of traditional tablets in the drug release rate and absorption of the metformin system. Active chewing gum containing Hoodia gordonii has been the most reduced and best-selling weight loss product in the US over the past decade. Hoodia acts by releasing a sugar-like substance (P57), but it has 100,000 times more energy, indicating the hypothalamus to eat enough food, which in turn suppresses appetite. The insertion directly into the chewing gum allows the supplement to be absorbed in seconds and pass through solubility and absorption problems.

\section{Conclusion}

Chewing gum not only offers therapeutic benefits but also is an attractive, unique and effective drug delivery system. Clinical trials have confirmed the benefits that can be gained by exploiting the effects of chewing gum, ease of delivery and opportunities for buccal absorption and local effect. The current manuscript presents many of the patented applications used in the field of chewing gum. Management of fungal infections, prevention of caries, smoking cessation, decaying gums. This article also provides insight into the various commercial speaker techniques used to treat chewing gums. With the advent of new applications and commercial technology forums, the area of chewing gum to be treated will continue to attract consumers.

It can be used for scheduled drug delivery where immediate action is required, such as motion sickness, nausea, pain, allergies and infections and high blood pressure (as long as the drug is easily absorbed orally). Since chewing gum is intended to be kept in the mouth for a long time, the removal of taste-masking remains an important factor in the growth of the product, as is the control of drug release on the basis of the gums. The simplicity and acceptance of chewing gums, combined with active flavor and taste, can lead to improved compliance. In the future, the concept of chewing gum as a drug delivery system may be used more often than opting for other oral drug delivery programs for local delivery and a highly prescribed drug system due to higher patient acceptance and compliance. In addition, MCG also benefits from the benefits of chewing gum such as oral care, stress relief, improved concentration, and weight management. 


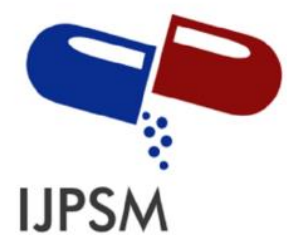

\section{Bhushan Mali et al, International Journal of Pharmaceutical Sciences and Medicine (IJPSM), Vol.6 Issue. 7, July- 2021, pg. 128-152}

ISSN: 2519-9889

Impact Factor: 3.426

\section{References}

[1]. Chien YW, 1992, Novel Drug Delivery Systems, Revised and expanded, Marcel Dekker, Ind edition, 139-40.

[2]. Chaudhary SA, Shahiwala AF., 2012, directly compressible medicated chewing gum formulation for quick relief from common cold. Int J Pharma Investig ; 2:123-33

[3]. Jette Jacobsen, Lona L. Christrup and Niels-Henrik Jensen,2004, Medicated Chewing Gum Pros and Cons, Healthcare Technology Review.

[4]. Lieberman HA, Lachman L, Schwartz JB, 1990, Pharmaceutical Dosage Forms: Tablets, Vol-I, Ind edition, 367-415.

[5]. Rassing MR, 1996, Specialized oral mucosal drug delivery systems: Chewing gums. In: Rathbone, M.J. (Ed.), Oral Muccosal Drug Delivery, Marcel Dekker, New York; 319-57.

[6]. Lieberman HA, Lachman L, Schwartz JB, 1990, Pharmaceutical Dosage Forms: Tablets, Vol-I, II ${ }^{\text {nd }}$ edition; 367-415

[7]. Turki A, Hagbani and Sami Nazzal, Medicated Chewing Gums (MCGs): Composition, Production, and Mechanical Testing.

[8]. Cherukuri SR, Friello DR, Ferroti M, Jewell M, D'Amelia RP,1982, Gum base, chewing gum containing same and method, U.S. Patent 4,352,822.

[9]. Kvist LC, Andersson SB, Berglund J, Wennergren B, Fors SM,2000, Equipment for drug release testing of medicated chewing gums, J Pharm and Biomed Ana; 22: 405-11.

[10].Nielsen HM, 2000, Ph.D. thesis, HC $\varnothing$ Tryk, Copenhagen, DK.

[11]. Dodds M, Hiesh S, Johnson D, 1991, The effect of increased mastication by daily gum chewing on salivary gland output \& dental plaque acidogenicity, J Dent Res; 70: 1474-1478.

[12]. Rassing MR, 1996, Specialized oral mucosal drug delivery systems: Chewing gums. In: Rathbone, M.J. (Ed.), Oral Muccosal Drug Delivery, Marcel Dekker, New York; 319-57.

[13]. Cherukuri SR, Friello DR, Ferroti M, Jewell M, D'Amelia RP, 1982, Gum base, chewing gum containing same and method, U.S. Patent 4,352,822.

[14].Puetter S, Szejtli J, 1993 Dec 29, inventors. Puetter Medice Chem Pharm, assignee. Chewing gum compositions. US patent EP0575977.

[15].Jacobsen J, Bjerregaard S, Pedersen M., 1995 Jun, Cyclodextrin inclusion complexes of restorative materials. Am J Dent; 8 (3): 137-9.

[16]. Morella A, Lukas S, 1992, inventors. Faulding (FH) \& Company Limited, assignee. Microcapsule composition and process. US patent CA 2,068,366.

[17]. Yang R, Randolph N, 1987 Jun 29, inventors. Werner-Lambert Company, assignee. Encapsula120. Christensen LV, Tran KT, Mohamed SE. Gum chewing and jaw muscle fatigue tion composition for use with chewing gum and edible products. US patent 4,740,376.

[18].Song JH, Greenberg MJ, Record DW, Zibell SE, Schnell PG, 1992, Gum composition containing dispersed porous beads containing active ingredients and method, U.S. Patent 5,154,927.

[19].Gutiérrez-López GF, Welti-Chanes J, Parada-Arias E., 2008, Food engineering: integrated approaches: Springer.

[20].Portal TS. Chewing gum market-statistics \& facts. 2015 [cited 20181 Feb]; Available from: https://www.statista.com/topics/ 1841/chewing-gum/.

[21]. Konar N, Palabiyik I, Toker OS, Sagdic O., 2016, Chewing gum: production, quality parameters and opportunities for delivering bioactive compounds. Trends Food Sci Technol. 55:29-38.

[22].Turki Al Hagbani, and Sami Nazzal, 2018, Review Article on Medicated Chewing Gums (MCGs): Composition, Production, and Mechanical Testing, AAPS PharmSciTech.

[23]. Aslani A, Rostami F., 2015, medicated chewing gum, a novel drug delivery system. J Res Med Sci., 20(4):403-11

[24].Jacobsen J, Christrup LL, Jensen N-H., 2004, medicated chewing gum. Am J Drug Delivery, 2(2):75-88

[25].Bhowmick AK, Stephens H., 2000, Handbook of elastomers: CRC.

[26].D'Sa AB, Group IoCP., 2012, Adhesives and consolidants in painting conservation: archetype publications. 


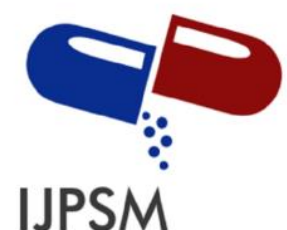

\section{Bhushan Mali et al, International Journal of Pharmaceutical Sciences and Medicine (IJPSM), Vol.6 Issue. 7, July- 2021, pg. 128-152}

ISSN: 2519-9889 Impact Factor: $\mathbf{3 . 4 2 6}$

[27].Weyland M, Hartel RW., 2008, Emulsifiers in confectionery. Food emulsifiers and their applications: Springer. p. 285305

[28].Hartel RW, Joachim H, Hofberger R., 2018, Confectionery science and technology: Springer.

[29]. Gibbs BF, Kermasha S, Alli I, Mulligan CN., 1999, Encapsulation in the food industry: a review. Int J Food Sci Nutr. 50(3):213-24.

[30].Chaudhary SA, Shahiwala AF., 2010, Medicated chewing gum—a potential drug delivery system. Expert Opin Drug Deliv.; 7(7):871-85.

[31].Pharmacopoeia E., 2014, General monograph on dissolution test for medicated chewing gums. European directorate for the quality of medicines. 8th ed: Council of Europe. p. 325.

[32].Shivang A Chaudhary \& Aliasgar F Shahiwala, 2013, Medicated chewing gum -- a potential drug delivery system Review article.

[33].Morjaria Y, Irwin WJ, Barnett PX, Chan RS, Conway B., 2004, In vitro release of nicotine from chewing gum formulations. Dissolut Technol.,11(2):12-5

[34].Barabolak R, Hoerman K, Kroll N, et al., 1991, Chewing gum profiles in the US population. Community Dent Oral Epidemiol., 19: 125-6

[35].Prerna Kaushik and Deepak Kaushik, 2019, Review Article, Medicated Chewing Gums: Recent Patents and Patented Technology Platforms, Recent Patents on Drug Delivery \& Formulation, 13, 184-191

[36].Pedro, J.L., Fuente, B., 2016, Health products with inactivated probiotics and their uses. EP3289888. 